\title{
Experimental Constraints on the Homogenization of Plagioclase Hosted Melt Inclusions from Plagioclase Ultraphyric Basalts
}

\author{
Kristen R. LeWIS ${ }^{1}$, GOKCE K. USTUNISIK ${ }^{1,2}$, Roger L. \\ NIELSEN ${ }^{1,3}$ \\ ${ }^{1}$ Department of Geology and Geological Engineering, \\ SDSM\&T, Rapid City, SD, 57701-3995, USA, \\ krlamfer@mtu.edu \\ ${ }^{2}$ Department of Earth and Planetary Sciences, AMNH, New \\ York, NY, 10024, USA \\ ${ }^{3}$ CEOAS, Oregon State Univ., Corvallis, OR 97730, USA
}

Plagioclase Ultraphyric Basalts (PUBs) are a component of the array of MORB lavas that contain $>15 \%$ plagioclase megacrysts and their melt inclusions (MI) that are not typically in equilibrium with the host liquid. This implies that they formed prior to fractionation and mixing. MI may be used to determine the melt composition at the time of entrapment once the effects of post-entrapment modification have been removed by homogenization. To interpret MI data, we must understand the character and magnitude of the processes that might affect the MI composition during the homogenization process. Previous work [1] noted a drift in composition with increasing homogenization time that was attributed to crystal relaxation. This observation raised an important question: Does confining pressure influence the major and trace element partitioning behavior between the plagioclase host and its MIs? To answer this question, we tested two hypothesis incuding 1) The progressive diffusion of $\mathrm{Mg}$, and potentially other elements, from the host plagioclase to or from the MI is caused by crystal relaxation and resultant reduction in pressure within the MI. 2) MIs preserve a disequilibrium phenomenon where the entrapped melt is not related to the host crystal and re-equilibrates during homogenization. Here we conducted homogenization experiments in the form of time series both at $1 \mathrm{~atm}$. (30 min, 4 hour, 1 day, 4 days, and 8 days), and at 7.5 kbar ( 2 days, and 4 days) using plagioclase megacrysts from two samples of differing anorthite content (Juan de Fuca and Blanco Fracture Zone). Our results show that both samples exhibit time dependent drift in major and trace element composition. Long homogenization times ( 4 and 8 days) exhibit $\mathrm{Mg}$ depletion halos in the surrounding plagioclase, while the high pressure experiments do not. This suggests that crystal relaxation and pressure are the controlling factors for the observed compositional changes with time.

[1] Drignon et al. (2019) Geochem Geophys Geosyst., 20, 109-199 